\title{
Parasitological detection and molecular evidence of Hepatozoon canis from canines in Manila, Philippines
}

This article was published in the following Dove Press journal:

Veterinary Medicine: Research and Reports

3I December 2010

Number of times this article has been viewed

\author{
Abigail M Baticados' \\ Waren N Baticados' \\ Enrique T Carlos ${ }^{2}$ \\ Sixto MEAS Carlos ${ }^{2}$ \\ Lorelie A Villarba' \\ Sherlyn G Subiaga' \\ Jomarte M Magcalas' \\ 'Department of Veterinary \\ Paraclinical Sciences, College \\ of Veterinary Medicine, University \\ of the Philippines Los Baños, Laguna, \\ Philippines; ${ }^{2}$ Makati Dog and Cat \\ Hospital (MDCH), Makati City, \\ Philippines
}

Correspondence: Abigail M Baticados College of Veterinary Medicine, University of the Philippines

Los Baños, Laguna, Philippines 403 I

Tel +63495362728

Fax +63495362730

Email ambaticados@uplb.edu.ph
Abstract: Hepatozoon canis infection in canines is allegedly an underreported disease in the Philippines. In over the past four decades, there are only two published cases in the country. A total of 168 canine blood samples was processed for polymerase chain reaction (PCR) amplification and blood parasite examination (BPE). The PCR method was able to provide molecular evidence for the presence of Hepatozoon canis genomic DNA in one sample $(0.6 \%)$. Consequently, Hepatozoon canis gametocytes demonstrating the classical elongated appearance in leucocytes were also consistently seen on Giemsa ${ }^{\circledR}$-stained blood smears of the PCR-positive animal after BPE. The study elucidates the parasitological detection and first molecular evidence of Hepatozoon canis infection in the Philippines by PCR.

Keywords: Hepatozoon canis, Manila, polymerase chain reaction, blood parasite examination

\section{Introduction}

Tick-borne infections are an emerging urban and rural problem in canines. One of the common but seemingly underreported tick-borne diseases of dogs in the Philippines is hepatozoonosis. In over the past four decades, there have been only two published cases in canines in the Philippines. ${ }^{1,2}$

Hepatozoon canis is a vector-borne blood parasite of carnivores, especially domesticated dogs, with a predilection for white blood cells (WBCs) and blood-forming organs (ie, spleen, bone marrow, and lymph nodes). ${ }^{3,4}$ Unlike any other arthropod-transmitted disease, the mode of infection is not through bites but rather by ingestion of the infected ticks. ${ }^{5,6}$ Dogs that inadvertently ingest the brown dog tick (Rhipicephalus sanguineus), with sporocyst stage formed after sporogony, will lead to the liberation of the sporozoite in the gut. This is followed by gut wall penetration, entrance into the blood circulation, and infection of the mononuclear cells which are disseminated to different target organs including the liver, spleen, and bone marrow to become a schizont. In every cycle of schizogony, a generation of schizonts is being formed. These schizonts are the source of the merozoites which eventually invade leucocytes to become elongated gamonts or gametocytes. Syngamy occurs after gametocytes in mononuclear cells are released in the tick gut. This further leads to the formation of oocysts in the tick's body cavity containing the infective sporozoite stage. ${ }^{7,8}$

The clinical manifestation of the disease may range from being asymptomatic (due to low parasitemia), to a severe disease with anemia and showing signs of lethargy and cachexia in dogs with high parasitemia. ${ }^{3}$ However, the main clinical signs include anorexia, fever, depression, weight loss, and lymphadenopathy in infected dogs. ${ }^{7,9}$ 
Classically, disease diagnosis of hepatozoonosis is based primarily on finding gametocytes in the monocytes or neutrophils of stained blood smears. However, microscopic blood parasite examination is often limited especially in terms of sensitivity in dealing with low grade infection levels. ${ }^{10}$ In general, microscopic examination is amenable for use in screening large numbers of animals; however, it has approximately $50 \%$ sensitivity. ${ }^{11}$ The advent of molecular biology led to the discovery of methods (ie, polymerase chain reaction [PCR]) for more reliable and accurate diagnosis.

During the examination of canine blood samples for hematozoic parasites randomly selected from different cities of Manila, Hepatozoon canis was identified using molecular and parasitological detection methods. The PCR method was able to provide molecular evidence for the presence of Hepatozoon canis genomic DNA in one sample $(1 / 168$; $0.6 \%$ ). Accordingly, several Hepatozoon canis gametocytes showing their classical elongated appearance in leucocytes were also observed on Giemsa ${ }^{\circledR}$-stained blood smears of the same animal after blood parasite examination. This paper therefore focuses on the molecular evidence and microscopic detection of Hepatozoon canis in canine blood samples.

\section{Materials and methods Dogs}

A total of 168 dogs from randomly selected areas of Manila was used in the study. Samples came from different cities, including Makati, Manila, Quezon, Muntinlupa, Parañaque, Mandaluyong, Caloocan, San Juan, Taguig, Pasig, Malabon, and Las Piñas. All dogs included in the study had a history of tick infestation.

\section{Blood parasite examination}

A sample of approximately $3 \mathrm{~mL}$ canine blood was collected from each dog's cephalic vein. A portion of the blood was used for blood smear preparation, and the remaining blood sample was stored in ethylenediaminetetraacetic acid (EDTA)-coated vacutainers and frozen at $-40^{\circ} \mathrm{C}$ for further parasite DNA isolation and PCR assay.

The Giemsa ${ }^{\circledR}$-stained (Gurr; BDH Chemicals Ltd, Glossop, UK) blood smears were examined to locate gametocytes in WBCs. Positive detection of infected cells were documented with a Canon Digital IXUS I, 5.0 megapixels camera (Canon, New York, NY).

\section{DNA extraction}

Parasite DNA extraction was performed as previously described. ${ }^{12-14}$ A total of $100 \mu \mathrm{L}$ of blood sample was pipetted off and transferred to a single $1.5 \mathrm{~mL}$ microcentrifuge tube. Nine volumes of extraction buffer and $10 \mu \mathrm{L} / \mathrm{mL}$ of proteinase $\mathrm{K}(100 \mu \mathrm{g} / \mathrm{mL})$ were added to the blood sample then incubated at $55^{\circ} \mathrm{C}$ for 12 hours. Phenolchloroform-isoamyl alcohol (PCI) at $\mathrm{pH} 8.0$ was mixed with the incubated samples and centrifuged at 14,000 rpm at room temperature for 10 minutes. The aqueous layer was transferred to a new microcentrifuge tube, and chloroform of equal volume was added to the layer and centrifuged as previously described. The aqueous layer was transferred to another tube and mixed with $1 \mathrm{~mL}$ of $99.5 \%$ ethanol and $10-15 \mu \mathrm{L}$ of $3 \mathrm{~mol} / \mathrm{L} \mathrm{NaCOOH}$ and similarly centrifuged at $14,000 \mathrm{rpm}$ for 10 minutes. Resulting solution was decanted, and $1 \mathrm{~mL}$ of $70 \%$ ethanol was added and centrifuged again at 14,000 rpm for 10 minutes. The extracted DNA pellet was afterwards air-dried at room temperature. Finally, 50-100 $\mu \mathrm{L}$ of Tris-EDTA buffer was mixed with the pellet, and samples were frozen at $-40^{\circ} \mathrm{C}$.

\section{PCR amplification}

PCR amplification was performed with $25 \mu \mathrm{L}$ reaction mixture containing $1 \mu \mathrm{L}$ of each DNA template, $200 \mu \mathrm{mol} / \mathrm{L}$ dNTP mixture, 20 pmoles of each primer (Figure 1A), distilled water, and $1.5 \mathrm{U}$ of Taq DNA polymerase in a $10 \times$ PCR reaction buffer. Autoclaved distilled water was used as negative control. Amplification was carried out using the following conditions: initial denaturation at $94^{\circ} \mathrm{C}$ for 5 minutes; 40 repeated cycles of denaturation at $94^{\circ} \mathrm{C}$

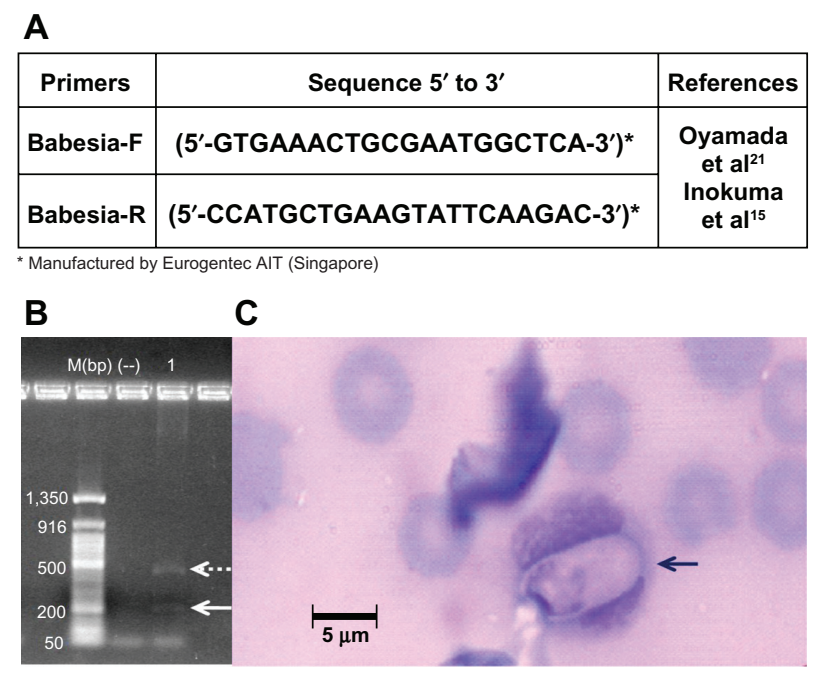

Figure I Hepatozoon canis in canine blood sample. A) The PCR primer pair used for the amplification. B) The amplicons indicative of $H$. canis parasite after gel electrophoresis analysis. White broken and solid arrows denote the approximately $500 \mathrm{bp}$ and $200 \mathrm{bp}$ PCR bands respectively. C) The gametocyte of $H$. canis in leukocyte (black arrow).

Abbreviations: bp, base pair; PCR, polymerase chain reaction. 
for 30 seconds, annealing at $45^{\circ} \mathrm{C}$ for 30 seconds, and chain extension at $72^{\circ} \mathrm{C}$ for 90 seconds. A final extension at $72^{\circ} \mathrm{C}$ for 5 minutes completed the last step. ${ }^{15}$

\section{Gel electrophoresis}

Amplicons were electrophoresed through 1.8\% TAE (Trisacetate-EDTA) agarose gel stained by ethidium bromide in the gel electrophoresis chamber (Bio-Rad, Philadelphia, PA). Observed results were photographed by a DigiDoc-It Imaging System (UVP, Upland, CA). Negative control was included, and a molecular weight marker served as an indicator of the product size and was used in the proper identification and estimation of PCR bands.

\section{Results and discussion}

The study endeavored to detect hemoparasites in canine blood samples using molecular and parasitological methods, and as a corollary, these diagnostic tests yielded molecular evidence and microscopic detection of Hepatozoon canis in canine blood samples.

Out of 168 Giemsa $^{\circledR}$-stained canine blood samples processed for blood parasite examination, only one animal $(1 / 168 ; 0.6 \%)$ was found infected with Hepatozoon canis gametocytes showing the classical elongated appearance in the leucocytes (Figure 1B). ${ }^{1,8}$ This percentage of infection was likewise reflected in the study of Jensen et al involving 153 dogs in Athens, Greece. ${ }^{16}$ It also reported that Hepatozoon canis was less frequently diagnosed $(0.7 \%)$ as compared with Ehrlichia canis (41.\%), Borrelia spp. (22.9\%), Leishmania (18.3\%), Dirofilaria immitis (13.1\%), and Babesia canis $(2.6 \%)$. In addition, Karagenc et al previously stated that in Turkey, a $10.6 \%$ prevalence of Hepatozoon canis was obtained after subjecting 349 canine blood samples to microscopic examination. ${ }^{17}$ Moreover, in Brazil, examination of 12 urban dogs showed that one out of the 12 animals $(8.3 \%)$ was positive using parasitological examination. ${ }^{18}$ Conversely, recent data by Menn et al from serological examination, exhibited that the least prevalent blood pathogen detected by antibody titers is Hepatozoon canis $(2.7 \%) .{ }^{19}$ The other parasites detected in ascending prevalence based on antibody titers were microfilariae (7.7\%), Ehrlichia canis (10.1\%), Leishmania infantum (12.2\%), and Babesia canis (23.4\%). Furthermore, the PCR detection of Hepatozoon canis in tick vectors (Ixodes ricinus) in central Europe also yielded low percentage of detection $(0.1 \%) .{ }^{20}$

In contrast, the study of Karagenc et al revealed that PCR assay was proven to have a higher sensitivity (25.8\%) compared with blood parasite examination $(10.6 \%) .{ }^{17}$ Molecular studies of Oyamada et al disclosed parallel findings wherein 33 dogs among the 78 total canine population (42.3\%) were positive for Hepatozoon species. ${ }^{21}$ Recently, the presence of Hepatozoon canis was reported in wild canids (Vulpes vulpes) from Italy. Out of 119 examined foxes by PCR assay, 16 foxes (13.4\%) were found harboring Hepatozoon canis. ${ }^{22}$ Likewise, the result of a molecular survey by Criado-Fornelio et al in Southern Europe described Hepatozoon canis in all 10 wild red foxes (Vulpes vulpes) sampled (100\%). ${ }^{23}$ In addition, Hepatozoon species and Hepatozoon canis were also seen in immature spotted hyenas (100\%) in Tanzania, water pythons (Liasis fuscus) (100\%) in Australia, and African wild dogs (Lycaon pictus) $(0.66 \%)$ in South Africa. ${ }^{24,25}$

Correspondingly, the study was able to amplify PCR bands (Figure 1B) associated with Hepatozoon canis genomic DNA in one sample $(1 / 168 ; 0.6 \%)$ using primer pair (Figure 1A) that were recently confirmed capable of detecting Hepatozoon canis DNA. ${ }^{21}$ Although, the expected 780 base pair (bp) amplicon for Hepatozoon spp. was not observed, PCR revealed two PCR bands ( $\sim 500$ bp and $\sim 200$ bp). The computational addition of the molecular weights (bp) of these two unexpected bands, however, resulted in an amplicon size of $\sim 700 \mathrm{bp}$. This variation in the results was most likely attributed to geographical or strain variation as commented by Little et al. ${ }^{26}$ Furthermore, microscopic identification of Hepatoozon canis gametocytes further reinforces the findings of PCR assay, since it is known that definitive diagnosis of Hepatozoon spp. can be made by direct detection of the pathogens in peripheral blood under the microscope. ${ }^{27}$ Consequently, Hepatoozon canis gametocytes were detected only from the PCR-positive sample, thus establishing that crude Hepatoozoon canis genomic DNA was indeed present.

In the likelihood that amplicons were to show high sequence similarity to Hepatozoon canis DNA sequence, this might be a manifestation of new data on the genetic and geographical variation of the parasite. Consequently, this will add to the usual reported cases of single base variations found in isolates from different animals which were merely considered as polymerase errors or rare polymorphisms in hypervariable regions. ${ }^{23,29}$ Moreover, according to the study of Gomes et al as cited by Ramadan et al, genetic variations or polymorphisms establish the possibility that genomic variants between organisms of the same species occur. ${ }^{30}$ If the amplicons were to come out as a homologue of several Hepatozoon canis clones stored in the public database, the present data may show that the Philippines may possibly harbor a different strain of Hepatozoon canis. Accordingly, the outcome of further study and verification of the sample 
and parasite species will have important implications in the epidemiology, diagnosis, and control of the vector-borne parasite (Hepatozoon canis) in the Philippines.

The study elucidates the parasitological detection of Hepatozoon canis in Manila, Philippines. Furthermore, this paper is a plausible indication of the first molecular evidence of Hepatozoon canis infection in the country by PCR assay.

\section{Acknowledgments}

The authors would like to express their sincere appreciation to Ms Julie Hufano and the MDCH staff, as well as Dr Paul Vincent Fajardo for their assistance during the survey and blood collection of samples.

\section{Disclosure}

The authors report no conflicts of interest in this work.

\section{References}

1. Carlos E, Atienza L, Cabiles C. A report on the presence of Hepatozoon canis in the Philippines. Philipp J Vet Med. 1971;10:181-189.

2. Novilla M, Kwapien R, Peneyra R. Occurrence of canine hepatozoonosis in the Philippines. Proc Helminthol Soc Wash. 1977;44:98-100.

3. Baneth G. Canine Hepatozoonosis - Two Different Diseases. Rhodes, Greece: 29th World Congress of the World Small Animal Veterinary Association; 2004.

4. Baneth G, Shkap V. Monozoic cysts of Hepatozoon canis. J Parasitol. 2003;89:379-381.

5. Smith TG. The genus Hepatozoon (Apicomplexa: Adeleina). J Parasitol. 1996;82:565-585.

6. Landau I. A comparison of the life cycles of Toxoplasma and Hepatozoon, with reference to the general phenomenon and the role of cyst formation in the coccidia. Ann Trop Med Parasitol. 1973;67:403-407.

7. Ivanov A, Tsachev I. Hepatozoon canis and hepatozoonosis in the dog. Trakia J Sci. 2008;6:27-35.

8. Soulsby E. Helminths, Arthropods and Protozoa of Domesticated Animals. 7th ed. London, UK: Baillière Tindall; 1982:689-690.

9. Pasa S, Kiral F, Karagenc T, Atasoy A, Seyrek K. Description of dogs naturally infected with Hepatozoon canis in the Aegean region of Turkey. Turk J Vet Anim Sci. 2009;33(4):289-295.

10. Ahantarig A, Trinachartvanit W, Milne JR. Tick-borne pathogens and diseases of animals and humans in Thailand. Southeast Asian J Trop Med Public Health. 2008;39(6):1015-1032.

11. Nantulya VM. Trypanosomiasis in domestic animals: the problems of diagnosis. Rev Sci Tech Off Int Epiz. 1990;9:357-367.

12. Sambrook J, Russell EW. Molecular cloning. In: A Laboratory Manual. 3rd ed. Cold Spring Harbor, NY: Cold Spring Harbor Laboratory Press; 2001:6.50-8.85.

13. Baticados WN, Inoue N, Sugimoto C, Nagasawa H, Baticados AM. Molecular cloning and sequencing of Trypanosoma brucei rhodesiense putative oligosaccharyl transferase. Online J Vet Res. 2010;14(1): $56-65$.

Veterinary Medicine: Research and Reports

\section{Publish your work in this journal}

Veterinary Medicine: Research and Reports is an international, peer-reviewed, open access journal publishing original research, case reports, editorials, reviews and commentaries on all areas of veterinary medicine. The manuscript management system is completely online and includes a very quick and fair peer-review system. Visit http://www.
14. Baticados WN, Inoue N, Sugimoto C, Nagasawa H, Baticados AM. Full-length DNA cloning, sequence analysis and transmembrane topology modelling of putative Trypanosoma brucei rhodesiense oligosaccharyl transferase (TbOST I). Online J Bioinform. 2010;11(1):162-176.

15. Inokuma H, Yoshizaki Y, Shimada Y, Sakata Y, Okuda M, Onishi T. Epidemiological survey of Babesia species in Japan performed with specimens from ticks collected from dogs and detection of new Babesia DNA closely related to Babesia odocoilei. J Clin Microbiol. 2003;41: 3494-3498.

16. Jensen J, Müller E, Daugschies A. Arthropod-borne diseases in Greece and their relevance for pet tourism. Prakt Tierarzt. 2003;84:430-438.

17. Karagenc TL, Pasa S, Kirli G, et al. A parasitological, molecular and serological survey of Hepatozoon canis infection in dogs around the Aegean coast of Turkey. Vet Parasitol. 2006;135(2):113-119.

18. Garcia de Sá A, Cerqueira ADF, O'Dwyer LH, et al. Detection of Hepatozoon spp in naturally infected brazilian dogs by polymerase chain reaction. Intern J Appl Res Vet Med. 2007;5(2):49.

19. Menn B, Lorentz S, Naucke TJ. Imported and travelling dogs as carriers of canine vector-borne pathogens in Germany. Parasit Vectors. 2010; $3(34): 1-7$.

20. Reye AL, Hübschen JM, Sausy A, Muller CP. Prevalence and seasonality of tick-borne pathogens in questing Ixodes ricinus ticks from Luxembourg. Appl Environ Microbiol. 2010;76(9):2923-2931.

21. Oyamada M, Davoust B, Boni M, et al. Detection of Babesia canis rossi, B. canis vogeli, and Hepatozoon canis in dogs in a village of Eastern Sudan by using a screening PCR and sequencing methodologies. Clin Diagn Lab Immunol. 2005;12(11):1343-1346.

22. Gabrielli S, Kumlien S, Calderini P, Brozzi A, Lori A, Cancrini G. The first report of Hepatozoon canis identified in Vulpes vulpes and ticks from Italy. Vector Borne Zoonotic Dis. 2010;10(9):855-859.

23. Criado-Fornelio A, Martinez-Marcos A, Buling-Saraña A, BarbaCarretero JC. Molecular studies on Babesia, Theileria and Hepatozoon in southern Europe Part I. Epizootiological aspects. Vet Parasitol. 2003; 113:189-201.

24. East ML, Wibbelt G, Lieckfeldt D, et al. A Hepatozoon species genetically distinct from H. canis infecting spotted hyenas in the Serengeti ecosystem, Tanzania. $J$ Wildl Dis. 2008;44(1):45-52.

25. Matjila PT, Leisewitz AL, Jongejan F, Bertschinger HJ, Penzhorn BL. Molecular detection of Babesia rossi and Hepatozoon sp. in African wild dogs (Lycaon pictus) in South Africa. Vet Parasitol. 2008;157: 123-127.

26. Little SE, Allen KE, Johnson EM, Panciera RJ, Reichard MV, Ewing SA. New developments in canine hepatozoonosis in North America: a review. Parasite Vectors. 2009;2(Suppl 1):S5.

27. Shkap V, Baneth G, Pipano E. Circulating antibodies to Hepatozoon canis demonstrated by immunofluorescence. JVet Diagn Invest. 1994; 6: 121-123.

28. Criado-Fornelio A, Rey-Valeiron C, Buling A, Barba-Carretero JC, Jefferies R, Irwin P. New advances in molecular epizootiology of canine hematic protozoa from Venezuela, Thailand and Spain. Vet Parasitol. 2007;114(3-4):261-269.

29. Ramadan NI, Saber LM, Latif MMAE, Abdalla NA, Ragab HM. Molecular genetic approach by using the RAPD-PCR technique for detection of genetic variability in non-human isolates of Fasciola. $\mathrm{J} \mathrm{Am}$ Sci. 2010;6(9):773-780.

\section{Dovepress}

dovepress.com/testimonials.php to read real quotes from published authors. 